\title{
Propriedades físicas de um Nitossolo Vermelho em função dos sistemas de uso e manejo
}

\author{
Indiamara Marasca', Fernanda C. Gonçalves', Maria H. Moraes', \\ Adriano W. Ballarin', Saulo P. S. Guerra' ${ }^{1}$ \& Kléber P. Lanças ${ }^{1}$
}

\begin{abstract}
RESUMO
O solo, um dos principais suportes da produção agrícola tem seu comportamento regido por um complexo conjunto de fatores físicos, químicos e biológicos, razão pela qual o presente trabalho teve como objetivo avaliar as modificações dos atributos físicos de um Nitossolo Vermelho distroférrico com diferentes manejos, na Faculdade de Ciências Agronômicas - UNESP, Campus de Botucatu, São Paulo, Brasil. O delineamento estatístico foi inteiramente casualizado, com seis repetições em três diferentes áreas, sendo uma área de mata nativa, uma área com sistema de preparo convencional do solo e uma área com plantio direto. Foram determinados: matéria orgânica, argila natural, porosidade total, macroporosidade, densidade do solo, resistência à penetração e diâmetro médio ponderado dos agregados. O sistema de preparo convencional apresentou os menores teores de matéria orgânica na camada até $0,20 \mathrm{~m}$. Na resistência à penetração não houve diferença entre os tratamentos. Para as cinco profundidades do sistema de preparo convencional observaram-se maior densidade e teor de argila natural em comparação aos outros sistemas. O sistema de preparo convencional diferiu dos demais tratamentos quanto ao diâmetro médio ponderado, porosidade total e macroporosidade apresentando os menores valores desses atributos.
\end{abstract}

Palavras-chave: densidade do solo, matéria orgânica e resistência mecânica do solo a penetração

\section{Physical properties of an distroferric Red Nitosol depending on the use and management systems}

\begin{abstract}
The soil is a mainstay of agricultural production, and its behavior governed by a complex set of physical, chemical and biological processes. The aim of this study was to evaluate the changes in the physical attributes of a distroferric Red Nitosol under different managements in the Faculty of Agricultural Sciences - UNESP, Botucatu, São Paulo, Brazil. The experimental design was completely randomized with six replications, in three diferent areas, an area with native forest, an area with conventional soil tillage and an area with no soil tillage. The organic matter, natural clay, total porosity, macroporosity, bulk density, penetration resistance and the mean diameter of the aggregates were determined. The conventional tillage had the lowest concentrations of organic matter in the layer up to $0,2 \mathrm{~m}$. For penetration resistance, no differences among treatments were observed. For the five depths of conventional tillage, higher density and natural clay content were observed, compared to other systems. The conventional tillage treatments differed from the others for the mean diameter, total porosity and macroporosity, as it had the lowest values of these attributes.
\end{abstract}

Key words: bulk density, organic matter and soil penetration resistance 


\section{INTRODUÇÃO}

O sistema plantio direto melhora as condições físicas do solo devido à maior produção de palha, favorecendo a infiltração de água, permitindo maior exploração do perfil do solo pelas raízes, diminuição do processo erosivo e, consequentemente, a manutenção da estabilidade do sistema (Chioderoli et al., 2012).

Em geral, são detectadas camadas subsuperficiais compactadas ocorridas provavelmente pelo intenso tráfego de máquinas e implementos agrícolas, ocasionadas por pressões na superfície do solo (Moraes \& Benez, 1996). O tráfego de máquinas agrícolas é apontado como fator determinante na ocorrência da compactação do solo (Veiga et al., 2007).

Indica-se um valor crítico de resistência à penetração de aproximadamente 1,7 e 1,9 MPa no que se refere ao crescimento e à produtividade de grãos de feijão e de soja, respectivamente (Lima et al., 2010).

Em solo compactado em que a resistência à penetração apresenta valores não impeditivos às plantas menores de 2,0 $\mathrm{MPa}$, é necessário manter maiores valores de água no solo. Nos solos cultivados com citros e culturas anuais verificaram-se valores excessivamente elevados de resistência à penetração em água no solo equivalente à capacidade de campo, indicando maior degradação da qualidade física do solo (Blainski et al., 2008)

A redução da macroporosidade pela compactação do solo promove menor crescimento das raízes, diminuição da quantidade de água disponível no solo reduzindo, direta ou indiretamente, a taxa de absorção de nutrientes pelas plantas (Mazza et al., 1994).

O acúmulo de matéria orgânica, que pode ocorrer a partir de um manejo adequado do solo e dos resíduos culturais e em áreas sob vegetação natural sem uso agrícola, geralmente está associado a uma melhora das condições físicas do solo (Campos et al., 1995).

Com o desenvolvimento agrícola a modificação da biomassa vegetal constitui a primeira transformação de importância no solo atuando diretamente na sua estrutura que, além das modificações na porosidade e densidade, provoca alterações que afetam a retenção de água e a resistência mecânica (Klein \& Câmara, 2007).

O efeito da matéria orgânica sobre o atrito das partículas dos solos depende de seus efeitos sobre a densidade e a retenção de água. Em baixos teores de água as substâncias orgânicas, por reterem fortemente a água, podem aumentar a fricção entre as partículas minerais (Soane, 1990) visto que impedem que a água se distribua uniformemente entre elas.

O objetivo do trabalho foi avaliar as modificações dos atributos físicos de um Nitossolo Vermelho distroférrico em sistema de preparo convencional e sistema plantio direto em comparação com área de mata nativa.

\section{MATERIAL E MÉTOdos}

O trabalho foi realizado na Fazenda Experimental Lageado, na Faculdade de Ciências Agronômicas, localizada no município de Botucatu, Estado de São Paulo.
O clima da região, segundo classificação de Cunha et al. (1999) e metodologia de Köppen, é Cwa, temperado quente (mesotérmico), com chuvas no verão e seca no inverno, com temperatura média do mês mais frio (julho) de $17,1{ }^{\circ} \mathrm{C}$ e do mês mais quente (fevereiro) de $23,3^{\circ} \mathrm{C}$ e precipitação média anual de $1.314 \mathrm{~mm}$.

O solo da área experimental é um Nitossolo Vermelho distroférrico textura muito argilosa (EMBRAPA, 2006).

$\mathrm{Na}$ Tabela 1 consta a caracterização física para os tratamentos avaliados.

Tabela 1. Caracterização física para mata nativa, preparo convencional e plantio direto

\begin{tabular}{cccccc}
\hline Manejos & Camadas & Areia grossa & Areia fina & Argila & Silte \\
\cline { 3 - 6 } Mata nativa & $\mathbf{( m )}$ & \multicolumn{3}{c}{$\mathbf{( \mathbf { g ~ k g } ^ { - 1 } \mathbf { ) }}$} \\
& 0,10 & 18 & 86 & 541 & 355 \\
& $0,10-0,20$ & 33 & 93 & 566 & 308 \\
& $0,20-0,30$ & 18 & 65 & 664 & 254 \\
& $0,30-0,40$ & 13 & 58 & 757 & 171 \\
& $0,40-0,50$ & 15 & 59 & 772 & 154 \\
\hline Convencional & $0-0,10$ & 17 & 60 & 662 & 261 \\
& $0,10-0,20$ & 14 & 53 & 705 & 228 \\
& $0,20-0,30$ & 10 & 53 & 701 & 236 \\
& $0,30-0,40$ & 13 & 50 & 706 & 231 \\
& $0,40-0,50$ & 10 & 55 & 703 & 232 \\
\hline Plantio direto & $0-0,10$ & 20 & 93 & 563 & 324 \\
& $0,10-0,20$ & 24 & 78 & 636 & 262 \\
& $0,20-0,30$ & 20 & 73 & 680 & 228 \\
& $0,30-0,40$ & 21 & 65 & 707 & 207 \\
& $0,40-0,50$ & 9 & 67 & 734 & 190 \\
\hline
\end{tabular}

O delineamento experimental foi o inteiramente casualizado, com seis repetições, que consistiu de uma área de mata nativa, uma área com sistema de preparo convencional do solo e uma área com plantio direto em substituição ao preparo convencional. Os resultados das análises físicas foram submetidos ao sistema computacional para análise de variância - SISVAR (Ferreira, 2000) e ao teste de Tukey a nível de 0,05 de probabilidade para comparação de médias.

O sistema de preparo convencional do solo utilizado nos últimos 20 anos foi manejado com duas gradagens intermediárias com $86,36 \mathrm{~cm}$ de diâmetro com $20 \mathrm{~cm}$ de profundidade e uma gradagem leve com $35,88 \mathrm{~cm}$ de diâmetro com $0,10 \mathrm{~m}$ de profundidade para quebrar os torrões maiores e possibilitar uma uniformidade maior da camada superficial do solo para a semeadura. Para realizar as operações de gradagem utilizou-se um trator com $80,9 \mathrm{~kW}$ no motor, 4 x 2 com TDA.

$\mathrm{O}$ sistema de preparo convencional do solo foi empregado nos últimos 5 anos para o cultivo de soja em sucessão com o milho.

O sistema de plantio direto foi implantado há 11 anos, seguindo as safras de inverno e verão, um ano com pousio cuja planta de cobertura foi a aveia.

Neste sistema de manejo foram utilizados um trator com $80,9 \mathrm{~kW}$ no motor, $4 \times 2$ com TDA e a semeadora com o sistema de fluxo contínuo equipada com 4 linhas para o milho espaçadas $0,90 \mathrm{~m}$ entre elas e 7 linhas para a soja espaçadas 0,45 m. O sistema de plantio direto foi manejado com dessecação com glifosato sendo $3 \mathrm{~L} \mathrm{ha}^{-1} \mathrm{e}$ a palhada picada com triturador horizontal de resíduos vegetais (triton) conforme a necessidade das plantas daninhas. 
A área com mata nativa apresenta árvores de grande porte mantidas há mais de 40 anos sem cultivo ou qualquer outro tipo de atividade antrópica; no presente estudo foi considerada área testemunha.

Para os três tratamentos foram abertas trincheiras com 1,5 $\mathrm{m}$ de profundidade e $1,0 \mathrm{~m}$ de largura e $1,5 \mathrm{~m}$ de comprimento para coleta das amostras. A coleta foi realizada nas camadas de 0-0,10, 0,10-0,20, 0,20-0,30, 0,30-0,40 e 0,40-0,50 m obtendose amostras deformadas e indeformadas com aneis volumétricos de $2,5 \mathrm{~cm}$ de altura e $5 \mathrm{~cm}$ de diâmetro. Foram coletadas 90 amostras sendo 30 por trincheira com 6 repetições para cada profundidade $(0-0,10,0,10-0,20,0,20-0,30,0,40-0,50$ e $0,50-$ $0,60 \mathrm{~m})$. A macroporosidade, argila natural que é dispersa em água e não sedimenta durante o período para a coleta do material, o diâmetro médio ponderado (DMP) e a densidade do solo foram determinados conforme EMBRAPA (1997).

A matéria orgânica foi determinada pelo método de Walkley e Black, adaptado e descrito por Raij et al. (2001) e a porosidade total com base em Danielson \& Sutherland (1986).

A resistência do solo a penetração (RP) foi obtida com uma máquina de ensaios servo-controlada marca EMIC, modelo 10, 000 MF célula tdr 19 com capacidade de carga $100 \mathrm{kN}$, faixa de variação de velocidade de $10 \mathrm{~mm} \mathrm{~min}^{-1} \mathrm{e}$ haste utilizada para resistência do solo, conforme ASAE (2000). Os aneis utilizados para os ensaios de RP foram os mesmos empregados para determinação de porosidade total, depois da umidade estar equilibrada a 0,06 MPa na mesa de tensão.

A força máxima (FMAX) foi a força atingida no ensaio; é obtida no ponto que caracteriza o pico no diagrama de ensaio e a energia de deformação (EDEF) que é a energia consumida na deformação (ou penetração, endentação) da amostra ao longo do ensaio; foi obtida pela integração da curva carga-deslocamento de ensaio, fornecendo um valor comparativo mais representativo do ensaio como um todo, diferentemente da força máxima, que foi um pico que ocorreu em determinado momento do ensaio. A energia de deformação é um parâmetro útil de comparação de amostras que apresentam diferentes resistências ao longo do ensaio; é, portanto, o caso típico de solos que, ao longo do processo de penetração, mobilizam diferentes resistências (de ponta e de atrito lateral). AEDEF também é utilizada no ensaio de endentação (penetração superficial) em materiais mais resistentes, como madeira, aço e concreto.

\section{Resultados E Discussão}

Para o sistema convencional de preparo do solo observa-se que o teor de matéria orgânica (MO) mostrou-se homogêneo em todas as camadas mas com diferença significativa $(p<0,05)$ na camada de 0-0,30 para a de 0,30-0,50 m, devido ao manejo que mobilizou o solo movimentando a $\mathrm{MO}$ nas profundidades (Tabela 2).

No PD houve diferença entre as camadas sendo que se observa, na camada de 0-0,20 m, maior concentração de MO, camada em que ocorre a adição de fertilizantes minerais e, em consequência, maior desenvolvimento das raízes, o que contribui com a adição de $\mathrm{MO}$ ao solo.

A mata apresentou o maior valor de $\mathrm{MO}$ entre os tratamentos para a camada de $0-0,10 \mathrm{~m}\left(43 \mathrm{~g} \mathrm{dm}^{-3}\right)$. Em relação às demais
Tabela 2. Matéria orgânica $\left(\mathrm{g} \mathrm{dm}^{-3}\right)$ para mata nativa, preparo convencional e plantio direto

\begin{tabular}{cccc}
\hline Camadas & \multicolumn{3}{c}{ Tratamentos } \\
\cline { 2 - 4 }$(\mathbf{m})$ & Convencional & Plantio direto & Mata nativa \\
$0-0,10$ & $20 \mathrm{~B} \mathrm{a}$ & $29 \mathrm{~A} \mathrm{a}$ & $43 \mathrm{~A} \mathrm{a}$ \\
$0,10-0,20$ & $17 \mathrm{~B} \mathrm{a}$ & $24 \mathrm{~A} \mathrm{~b}$ & $26 \mathrm{~A} \mathrm{~b}$ \\
$0,20-0,30$ & $10 \mathrm{C} \mathrm{bc}$ & $17 \mathrm{~B} \mathrm{c}$ & $24 \mathrm{~A} \mathrm{ac}$ \\
$0,30-0,40$ & $11 \mathrm{~B} \mathrm{~cd}$ & $12 \mathrm{~B} \mathrm{~d}$ & $20 \mathrm{~A} \mathrm{~cd}$ \\
$0,40-0,50$ & $9 \mathrm{~B} \mathrm{~d}$ & $11 \mathrm{~B} \mathrm{~d}$ & $18 \mathrm{~A} \mathrm{~d}$ \\
\hline
\end{tabular}

$\mathrm{CV}=13,69 ; \mathrm{DP}=2,66 ;$ As médias seguidas das mesmas letras maiúsculas no sentido das linhas e minúsculas no sentido das colunas, não diferiram significativamente entre si, pelo teste de Tukey, a nível de 0,05

camadas os valores de MO diminuíram com o aumento da profundidade do solo.

Entre os sistemas de manejo os teores de $\mathrm{MO}$ foram maiores para área de mata. Comparando-se os sistemas de preparo convencional e plantio direto observa-se, para este último, maior teor de MO na camada de 0 a $0,50 \mathrm{~m}$.

Para os sistemas de uso e manejo do solo avaliados há um acúmulo de MO nas camadas de superfície e decréscimo nos valores, com aumento da profundidade (Tabela 2 ).

$\mathrm{Na}$ camada de 0 a $0,20 \mathrm{~m}$ a mata nativa e o plantio direto apresentaram maiores teores de $\mathrm{MO}$ em comparação ao preparo convencional do solo. Para as camadas mais profundas, entre 0,20 e $0,50 \mathrm{~m}$, tanto para a mata nativa como para o plantio direto houve uma diminuição significativa nos valores de MO do solo em comparação com a mata nativa. Este resultado ocorre devido à deposição de resíduos orgânicos nas camadas mais superficiais, principalmente nos sistemas sem preparo e revolvimento do solo como sob mata nativa e plantio direto (Pacheco \& Cantalice, 2011)

A densidade do solo resultou em diferença entre os tratamentos com maiores valores para o manejo convencional, na camada de $0-0,30 \mathrm{~m}$, em comparação com o plantio direto $\mathrm{e}$ mata nativa, que não diferiram entre si (Tabela 3 ).

Tabela 3. Densidade do solo $\left(\mathrm{kg} \mathrm{dm}^{-3}\right)$ para mata nativa, preparo convencional e plantio direto

\begin{tabular}{cccc}
\hline Camadas & \multicolumn{3}{c}{ Tratamentos } \\
\cline { 2 - 4 }$(\mathbf{m})$ & Convencional & Plantio direto & Mata nativa \\
$0-0,10$ & $1,47 \mathrm{~A} \mathrm{a}$ & $1,27 \mathrm{AB} \mathrm{a}$ & $1,17 \mathrm{~B} \mathrm{a}$ \\
$0,10-0,20$ & $1,48 \mathrm{~A} \mathrm{a}$ & $1,24 \mathrm{~B} \mathrm{a}$ & $1,25 \mathrm{~B} \mathrm{a}$ \\
$0,20-0,30$ & $1,48 \mathrm{~A} \mathrm{a}$ & $1,25 \mathrm{~B} \mathrm{a}$ & $1,26 \mathrm{~B} \mathrm{a}$ \\
$0,30-0,40$ & $1,37 \mathrm{~A} \mathrm{a}$ & $1,25 \mathrm{~A} \mathrm{a}$ & $1,29 \mathrm{~A} \mathrm{a}$ \\
$0,40-0,50$ & $1,47 \mathrm{~A} \mathrm{a}$ & $1,28 \mathrm{~A} \mathrm{a}$ & $1,35 \mathrm{~A} \mathrm{a}$ \\
\hline
\end{tabular}

$\mathrm{CV}=10,21 ; \mathrm{DP}=0,13$; As médias seguidas das mesmas letras maiúsculas nas linhas $\mathrm{e}$ minúsculas nas colunas, não diferiram significativamente entre si, pelo teste de Tukey, a nível de 0,05 de probabilidade

O tráfego das máquinas agrícolas aumenta a densidade do solo, diminui o diâmetro médio ponderado e a macroporosidade na linha de rodado em relação à linha de plantio, o que causa degradação cumulativa da qualidade física do solo, ao longo dos anos de cultivo (Roque et al., 2010).

Com relação à curva de densidade do solo e o teor de água (Figura 1) observaram-se diferenças para as áreas sob preparo convencional, plantio direto e mata nativa.

Para o preparo convencional foram observados os maiores valores de densidade do solo ( $\mathrm{Ds}=1,47 \mathrm{~kg} \mathrm{dm}^{-3}$ ) em comparação com as demais áreas (Ds $=1,45 \mathrm{~kg} \mathrm{dm}^{-3}$ para o plantio direto $\mathrm{eDs}$ $=1,40 \mathrm{~kg} \mathrm{dm}^{-3}$ mata nativa) para um mesmo teor de água (29\%), 

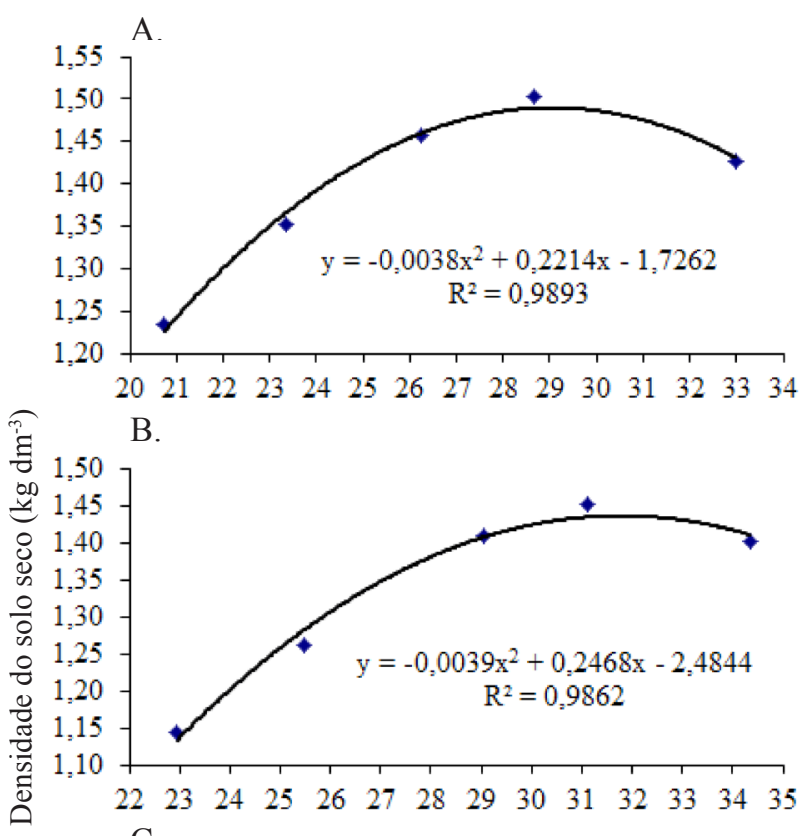

C.

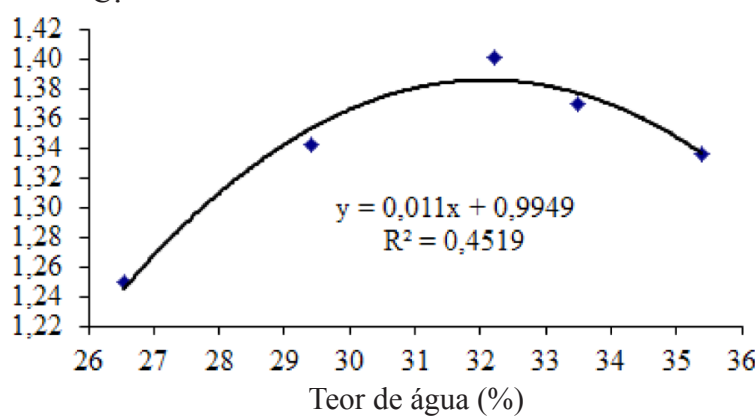

Figura 1. Relação da densidade do solo com o teor de água no solo para as áreas avaliadas: convencional (A), plantio direto (B) e mata nativa (C)

resultado que pode ser atribuído à maior espessura dos filmes de água ao redor das partículas uma vez que sob este sistema de preparo do solo há um teor menor de MO. Para um mesmo teor de água quanto maior for o teor de MO maiores também serão o atrito e a resistência à reorganização das partículas e, em contrapartida, menores os valores de densidade do solo.

Brandt (2005) mostrou, através das curvas de compactação de um Argiloso Vermelho-Amarelo distrófico arênico, que a palha de milho (12 $\mathrm{Mg} \mathrm{ha}^{-1}$ ) foi responsável pela dissipação de 3,27; 6,80 e $11,58 \mathrm{kgf} \mathrm{cm}^{-2}$ de energia aplicada e que, quando aplicados 15 golpes, ou seja, a energia equivalente de $3,27 \mathrm{kgf} \mathrm{cm}^{-2}$, a palha de milho absorveu $2,98 \%$ da energia aplicada. Com o aumento da energia aplicada, utilizando-se 30 golpes (energia equivalente $6,80 \mathrm{kgf} \mathrm{cm}^{-2}$ ), a palha de milho absorveu o equivalente a $8,20 \%$ da energia que foi aplicada sobre o solo. Com a aplicação de 50 golpes (energia equivalente $11,58 \mathrm{kgf} \mathrm{cm}^{-2}$ ) a palha de milho absorveu $8,60 \%$ da energia aplicada sobre o solo.

O sucesso desses sistemas no cerrado se deve ao fato de que a palhada acumulada pelas plantas de cobertura ou das pastagens e restos culturais de lavouras comerciais, proporciona um ambiente favorável à recuperação ou manutenção das propriedades do solo (Santos et al., 2008). Portanto, a presença de uma boa cobertura do solo é importante para promover melhoria das condições físicas e químicas em médio prazo e contribuir com a produção e o desenvolvimento das plantas (Chioderoli et al., 2012).

Para o diâmetro médio ponderado (DMP) foram encontradas diferenças entre as áreas em preparo convencional do solo e mata nativa, sendo os maiores valores observados para esta última condição (Tabela 4). As referidas diferenças decorrem do fato de não haver ação antrópica na área com mata nativa com acúmulo de $\mathrm{MO}$, o que contribui para a formação de agregados no solo. Sob preparo convencional há diminuição no DMP uma vez que a ação dos implementos de preparo do solo promove quebra acarretando uma proporção maior de agregados de menor diâmetro, o que contribui para os menores valores de DMP. O solo sob plantio direto apresenta uma situação intermediária entre as áreas sob preparo convencional e mata nativa. Os 12 anos de uso com o sistema promoveram maior adição de $\mathrm{MO}$ e melhor agregação das partículas do solo; outro fator que contribuiu é o fato de não haver quebra de agregados pelo preparo do solo.

Tabela 4. Diâmetro médio ponderado dos agregados $(\mathrm{mm})$ para mata nativa, preparo convencional e plantio direto

\begin{tabular}{cccc}
\hline \multirow{2}{*}{ Camadas $(\mathbf{m})$} & \multicolumn{3}{c}{ Tratamentos } \\
\cline { 2 - 4 } $0-0,10$ & Convencional & Plantio direto & Mata Nativa \\
$0,10-0,20$ & $1,29 \mathrm{~B} \mathrm{a}$ & $1,44 \mathrm{AB}$ a & $1,68 \mathrm{~A} \mathrm{a}$ \\
$0,20-0,30$ & $1,01 \mathrm{~B} \mathrm{a}$ & $1,45 \mathrm{AB}$ a & $1,67 \mathrm{~A} \mathrm{a}$ \\
$0,30-0,40$ & $1,15 \mathrm{~B} \mathrm{ab}$ & $1,35 \mathrm{AB}$ a & $1,67 \mathrm{~A} \mathrm{a}$ \\
$0,40-0,50$ & $0,81 \mathrm{~B} \mathrm{~b}$ & $1,37 \mathrm{AB} \mathrm{a}$ & $1,63 \mathrm{~A} \mathrm{a}$ \\
& $1,21 \mathrm{~A} \mathrm{a}$ & $1,51 \mathrm{~A} \mathrm{a}$ \\
\hline
\end{tabular}

$\mathrm{CV}=15,93 ; \mathrm{DP}=0,22 ;$ As médias seguidas das mesmas letras maiúsculas no sentido das linhas e minúsculas no sentido das colunas, não diferiram significativamente entre si, pelo teste de Tukey, a nível de 0,05

Maiores valores de DMP em área de mata nativa também foram observados por Assis \& Lanças (2010) como resultado do acúmulo de matéria orgânica e de não ocorrer ação antrópica por mais de quarenta anos, fatores que influenciaram fortemente a agregação do solo. Sob sistema de preparo convencional ocorreu fracionamento dos agregados maiores em unidades menores o que causou modificações significativas em relação às características originais, que foram mais afetadas quanto maior a intensidade do preparo do solo.

Áreas com milho sob sistema de preparo convencional do solo também apresentaram menores valores de DMP, o que foi atribuído por Lima et al. (2009) às operações de aração e gradagem que rompem os agregados de maior tamanho ocasionando acúmulo de agregados de classes de menor diâmetro.

Silva et al. (2008) constataram maior agregação nos sistemas em equilíbrio com também maiores teores de matéria orgânica e boa diversidade e atividade microbiana na massa do solo enquanto Perusi \& Carvalho (2007) enfatizam a importância da matéria orgânica na estabilidade dos agregados do solo.

Quanto ao teor de argila dispersa em água verificaram-se, para o sistema de preparo convencional do solo, maiores valores para todas as camadas avaliadas enquanto para o sistema de plantio direto houve diferença entre camadas de 0 a $0,20 \mathrm{~m}$ (Tabela 5).

Esses resultados podem ser atribuídos à quebra de agregados e à liberação de partículas individualizadas no sistema de 
Tabela 5. Argila dispersa em água para mata nativa, preparo convencional e plantio direto

\begin{tabular}{cccc}
\hline Camadas & \multicolumn{3}{c}{ Tratamentos } \\
\cline { 2 - 4 }$(\mathbf{m})$ & Convencional & Plantio direto & Mata Nativa \\
$0-0,10$ & $308 \mathrm{~A} \mathrm{a}$ & $301 \mathrm{~A} \mathrm{a}$ & $287 \mathrm{~A} \mathrm{a}$ \\
$0,10-0,20$ & $322 \mathrm{~A} \mathrm{a}$ & $290 \mathrm{~A} \mathrm{a}$ & $101 \mathrm{~B} \mathrm{~b}$ \\
$0,20-0,30$ & $348 \mathrm{~A} \mathrm{a}$ & $0 \mathrm{~B} \mathrm{~b}$ & $16 \mathrm{~B} \mathrm{~b}$ \\
$0,30-0,40$ & $347 \mathrm{~A} \mathrm{a}$ & $1 \mathrm{~B} \mathrm{~b}$ & $2 \mathrm{~B} \mathrm{~b}$ \\
$0,40-0,50$ & $420 \mathrm{~A} \mathrm{a}$ & $2 \mathrm{~B} \mathrm{~b}$ & $1 \mathrm{~B} \mathrm{~b}$ \\
\hline
\end{tabular}

$\mathrm{CV}=47,18 ; \mathrm{DP}=86,38 ;$ As médias seguidas das mesmas letras maiúsculas no sentido das linhas e minúsculas no sentido das colunas, não diferiram significativamente entre si, pelo teste de Tukey, a nível de 0,05

preparo convencional, associadas à utilização de corretivos e fertilizantes que contribuem com o processo de dispersão. Desta forma, as partículas podem ser translocadas para as camadas de maior profundidade.

Para o sistema de plantio direto pode-se atribuir os maiores valores observados na camada de $0-0,20 \mathrm{~m}$ à ação do disco de semeadura e à deposição de fertilizantes que contribuem para a dispersão das partículas de argila do solo.

Com referência à porosidade total, constatou-se diferença entre os sistemas de uso e manejo do solo para a camada de 0 a $0,30 \mathrm{~m}$ (Tabela 6).

Tabela 6. Porosidade total para mata nativa, preparo convencional e plantio direto

\begin{tabular}{cccc}
\hline Camadas & \multicolumn{3}{c}{ Tratamentos } \\
\cline { 2 - 4 }$(\mathbf{m})$ & Convencional & Plantio direto & Mata nativa \\
$0-0,10$ & $0,45 \mathrm{~B} \mathrm{a}$ & $0,52 \mathrm{AB} \mathrm{a}$ & $0,56 \mathrm{~A} \mathrm{a}$ \\
$0,10-0,20$ & $0,44 \mathrm{~B} \mathrm{a}$ & $0,54 \mathrm{~A} \mathrm{a}$ & $0,53 \mathrm{~A} \mathrm{a}$ \\
$0,20-0,30$ & $0,44 \mathrm{~B} \mathrm{a}$ & $0,53 \mathrm{~A} \mathrm{a}$ & $0,53 \mathrm{~A} \mathrm{a}$ \\
$0,30-0,40$ & $0,49 \mathrm{~A} \mathrm{a}$ & $0,53 \mathrm{~A} \mathrm{a}$ & $0,48 \mathrm{~A} \mathrm{a}$ \\
$0,40-0,50$ & $0,49 \mathrm{~A} \mathrm{a}$ & $0,52 \mathrm{~A} \mathrm{a}$ & $0,45 \mathrm{~A} \mathrm{a}$ \\
\hline
\end{tabular}

$\mathrm{CV}=10,57 ; \mathrm{DP}=0,05 ;$ As médias seguidas das mesmas letras maiúsculas no sentido das linhas e minúsculas no sentido das colunas, não diferiram significativamente entre $\mathrm{s}$, pelo teste de Tukey, a nível de 0,05

Para a camada superficial entre $0,00-0,10 \mathrm{~m}$ observaram-se maiores valores de porosidade total para a área com mata nativa (entre 0,56 e $0,45 \mathrm{~m}^{3} \mathrm{~m}^{-3}$ ) e plantio direto (entre 0,52 e 0,54 $\mathrm{m}^{3} \mathrm{~m}^{-3}$ ) resultados esses decorrentes do maior teor de MO nos sistemas PD e MN e da diminuição no tamanho de agregados do solo sob sistema de preparo convencional, conforme comentam Loss et al. (2010).

Segundo Klein et al. (2008) a maior porosidade do solo e as alterações provocadas na distribuição do diâmetro dos poros e na dinâmica da água, foram alteradas e o plantio direto escarificado apresentou maior porosidade de aeração em todo o período. Com a escarificação do solo sob sistema plantio direto, realizada há seis anos, ocorreram aumento do rendimento de grãos de trigo semeado sete meses após a escarificação e diminuição da densidade e da densidade relativa do solo aumentando a porosidade total e a porosidade livre de água durante o ciclo da cultura do trigo.

Os sistemas de uso e manejo do solo estudado resultaram em diferenças quanto à macroporosidade (Tabela 7).

A área com preparo convencional do solo apresentou os menores valores de macroporosidade, em todas as camadas, resultado coerente com os menores valores de MO e de DMP e à quebra dos agregados pelo uso de equipamentos agrícolas (Zalamena, 2008).
Tabela 7. Macroporosidade do solo para mata nativa, preparo convencional e plantio direto

\begin{tabular}{cccc}
\hline Camadas & \multicolumn{3}{c}{ Tratamentos } \\
\cline { 2 - 4 }$(\mathbf{m})$ & Convencional & Plantio direto & Mata nativa \\
$0-0,10$ & $0,12 \mathrm{~B} \mathrm{a}$ & $0,22 \mathrm{~A} \mathrm{a}$ & $0,23 \mathrm{~A} \mathrm{a}$ \\
$0,10-0,20$ & $0,14 \mathrm{~B} \mathrm{a}$ & $0,23 \mathrm{~A} \mathrm{a}$ & $0,23 \mathrm{~A} \mathrm{a}$ \\
$0,20-0,30$ & $0,18 \mathrm{~A} \mathrm{a}$ & $0,19 \mathrm{~A} \mathrm{a}$ & $0,26 \mathrm{~A} \mathrm{a}$ \\
$0,30-0,40$ & $0,13 \mathrm{~B} \mathrm{a}$ & $0,23 \mathrm{~A} \mathrm{a}$ & $0,23 \mathrm{~A} \mathrm{a}$ \\
$0,40-0,50$ & $0,13 \mathrm{~B} \mathrm{a}$ & $0,23 \mathrm{~A} \mathrm{a}$ & $0,23 \mathrm{~A} \mathrm{a}$ \\
\hline
\end{tabular}

$\mathrm{CV}=34,24 ; \mathrm{DP}=0,07 ;$ As médias seguidas das mesmas letras maiúsculas no sentido das linhas e minúsculas no sentido das colunas, não diferiram significativamente entre si, pelo teste de Tukey, a nível de 0,05

$\mathrm{Na}$ Tabela 8 estão representadas, para cada tratamento e camada avaliada, a força máxima (FMAX) e a energia de deformação (EDEF) encontradas para as amostras com umidade equilibrada.

Tabela 8. Força máxima e energia de deformação do solo para mata nativa, preparo convencional e plantio direto

$\begin{array}{rrrr}\text { Camadas (m) } & \text { Convencional } & \begin{array}{c}\text { Plantio direto } \\ \text { FMAX (N) }\end{array} & \text { Mata } \\ 0-0,10 & 11,91 \mathrm{~A} \mathrm{a} & 13,49 \mathrm{~A} \mathrm{a} & 9,42 \mathrm{~A} \mathrm{a} \\ 0,10-0,20 & 11,34 \mathrm{~A} \mathrm{a} & 10,17 \mathrm{~A} \mathrm{a} & 9,77 \mathrm{~A} \mathrm{a} \\ 0,20-0,30 & 9,30 \mathrm{~A} \mathrm{a} & 10,64 \mathrm{~A} \mathrm{a} & 6,57 \mathrm{~A} \mathrm{a} \\ 0,30-0,40 & 9,27 \mathrm{~A} \mathrm{a} & 7,27 \mathrm{~A} \mathrm{a} & 8,16 \mathrm{~A} \mathrm{a} \\ 0,40-0,50 & 14,59 \mathrm{~A} \mathrm{a} & 11,23 \mathrm{~A} \mathrm{a} & 8,99 \mathrm{~A} \mathrm{a} \\ \text { CV }(\%) & & 53,93 & \\ \text { DP } & & 5,47 & \\ & & \text { EDEF }(\mathrm{Nmm}) \\ 0-0,10 & 152,82 \mathrm{~A} \mathrm{a} & 139,34 \mathrm{~A} \mathrm{a} & 125,34 \mathrm{~A} \mathrm{a} \\ 0,10-0,20 & 129,54 \mathrm{~A} \mathrm{a} & 131,00 \mathrm{~A} \mathrm{a} & 115,46 \mathrm{~A} \mathrm{a} \\ 0,20-0,30 & 123,72 \mathrm{~A} \mathrm{a} & 145,36 \mathrm{~A} \mathrm{a} & 85,81 \mathrm{~A} \mathrm{a} \\ 0,30-0,40 & 145,53 \mathrm{~A} \mathrm{a} & 96,59 \mathrm{~A} \mathrm{a} & 96,61 \mathrm{~A} \mathrm{a} \\ 0,40-0,50 & 163,94 \mathrm{~A} \mathrm{a} & 129,08 \mathrm{~A} \mathrm{a} & 120,16 \mathrm{~A} \mathrm{a} \\ \text { CV }(\%) & & 48,17 & \\ \text { DP } & & 61,03 & \end{array}$

As médias seguidas das mesmas letras maiúsculas no sentido das linhas e minúsculas no sentido das colunas, não diferiram significativamente entre si, pelo teste de Tukey a nível de 0,05

Nenhuma das propriedades avaliadas, força máxima $(\mathrm{N})$ e energia de deformação a $25 \mathrm{~mm}$, foi mais estável; entretanto, torna-se necessário aumentar a quantidade de amostras utilizadas. O parâmetro que parece ser o mais expressivo, já que cataliza a força e profundidade de penetração, é a força $\mathrm{N}$ ao longo da ponteira seguido da energia quando atinge $25 \mathrm{~mm}$; na Figura 2 estão representados os valores de resistência à penetração do solo para os diferentes manejos avaliados.

As avaliações não sinalizaram diferença estatística entre os tratamentos quando se tem água em equilibrio no solo para os diferentes manejos. Nas demais camadas o tratamento com preparo convencional apresentou os maiores valores de resistência à penetração do solo.

Brandt (2005) observou, para os dados de resistência à penetração (RP), que não houve diferença significativa entre os tratamentos nas menores profundidades e diferença significativa nas profundidades de 25,00 a $28,50 \mathrm{~mm}$, que não devem ser afetadas pelos diferentes manejos do solo. Os dados de RP apresentados foram obtidos oito meses após a escarificação mostrando que a reacomodação do solo foi rápida e que o revolvimento do solo, tanto com escarificação 


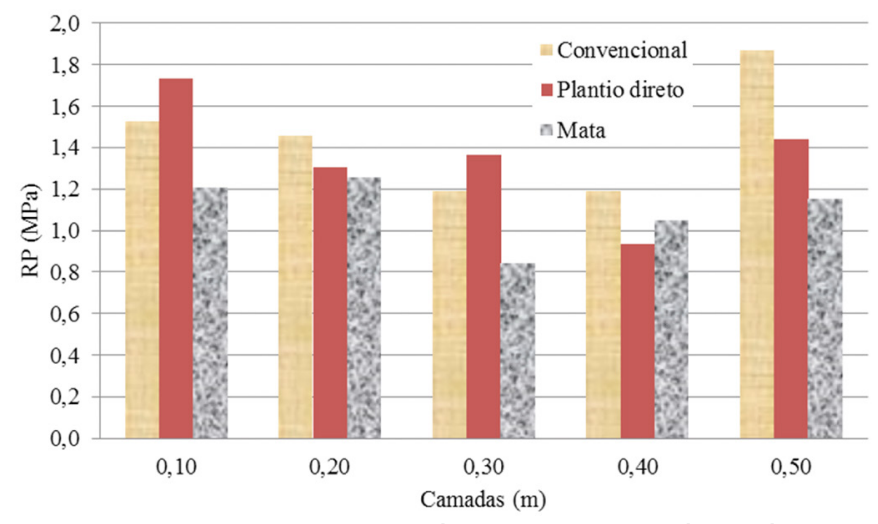

Figura 2. Histograma da resistência do solo à penetração (RP) nos diferentes manejos avaliados

como com a lavração, não tem efeito na RP do solo, com o passar do tempo.

\section{Conclusões}

1. A substituição do preparo convencional pelo plantio direto promove aumento do teor de matéria orgânica na camada superficial e melhoria nas propriedades físicas do solo.

2. O preparo convencional tem efeito prejudicial na estrutura do solo e causa aumento na densidade do solo, argila dispersa em água e resistência à penetração, além de diminuição no diâmetro médio ponderado dos agregados, porosidade total e macroporosidade do solo.

\section{Literatura Citada}

ASAE - American Society of Agricultural Engineers. Soil cone penetrometer. Saint Joseph: ASAE, 2000. 833p.

Assis, R. L; Lanças, K, P. Agregação de um nitossolo vermelho distroférrico sob sistemas de plantio direto, preparo convencional e mata nativa. Engenharia Agrícola, v.30, p.58-66, 2010.

Blainski, E.; Tormena, G.A.; Fidalski, J.; Guimarães, R.M.L. Quantificação da degradação do solo por meio da curva de resistência do solo à penetração. Revista Brasileira de Ciência do Solo, v.32, p.975-983, 2008.

Brandt, A. A. Propriedades mecânicas do solo franco arenoso sob distintos sistemas de preparo, tráfego mecanizado e resíduos vegetais. Santa Maria: UFSM, 2005. 90p. Dissertação Mestrado

Campos, B. C.; Reinert, D. J.; Nicolodi, R.; Ruedell, J.; Petrere, C. Estabilidade estrutural de um Latossolo Vermelho-Escuro distrófico após sete anos de rotação de culturas e sistemas de manejo de solo. Revista Brasileira de Ciência do Solo, v.19, p.121-126, 1995.

Chioderoli, C. A.; Mello, L. M.; Grigolli, P. J; Furlani, C. E. A.; Silva, J. O. R.; Cesarin, A. L. Atributos físicos do solo e produtividade de soja em sistema de consórcio milho e braquiária. Revista Brasileira de Engenharia Agrícola e Ambiental, v.16, p.37-43, 2012.
Cunha, A. R.; Klosowski, E. S.; Galvani, E. J. F.; Escobedo, M., D. Classificação climática para o município de Botucatu, SP, segundo Köppen. In: Simpósio em Energia Na Agricultura, 1, 1999, Botucatu. Anais... Botucatu: FCA/UNESP, 1999. p.487-491.

Danielson, R. E.; Sutherland, P. L. Porosity. In: Klute, A. (ed.) Methods of soil analysis. Madison: American Society Agronomy, v.1, p.545-66, 1986.

EMBRAPA - Empresa Brasileira de Pesquisa Agropecuária. Centro Nacional de Pesquisa de Solos. Manual de métodos de análise de solo. Rio de Janeiro: EMBRAPA, 1997. 212p.

EMBRAPA - Empresa Brasileira de Pesquisa Agropecuária. Centro Nacional de Pesquisa de Solos. Sistema brasileiro de classificação de solos. 2.ed. Rio de Janeiro: EMBRAPA, 2006. 306p.

Ferreira, D. F. Análise estatística por meio do SISVAR (Sistema para Análise de Variância) para Windows versão 4.0. In: Reunião Anual da Região Brasileira da Sociedade Internacional de Biometria, 45, 2000, São Carlos. Anais. São Carlos: UFSCar, 2000. p.255-258.

Klein, V. A.; Câmara, R. K. Rendimento da soja e intervalo hídrico ótimo em latossolo vermelho sob plantio direto escarificado. Revista Brasileira de Ciência do Solo, v.31, p.221-227, 2007.

Klein, V. A; Vieira, M. L; Durigon, F. F; Massing, J. P; Fávero, F. Porosidade de aeração de um Latossolo Vermelho e rendimento de trigo em plantio direto escarificado. Ciência Rural, v.38, p.365-371, 2008.

Lima, A. G. de; Loss, A.; Pereira, M.; Anjos, L. H. C. dos; Silva, E. M. R. da. Distribuição dos agregados e diâmetro médio ponderado avaliados em diferentes sistemas de produção orgânica. Revista Brasileira de Agroecologia, v.4, p.13021305, 2009.

Lima, C. L. R.; Reinert, D. J.; Reichert, J. M.; Suzuki, L. E. A. S. Produtividade de culturas e resistência à penetração de Argissolo Vermelho sob diferentes manejos. Pesquisa Agropecuária Brasileira, v.45, p.89-98, 2010.

Loss, A.; Pereira, M. G.; Schultz, N.; Anjos, L. H. C. dos; Silva, E. M. R. da. Quantificação do carbono das substâncias húmicas em diferentes sistemas de uso do solo e épocas de avaliação. Bragantia, v.69, p.913-922, 2010.

Mazza, J. A.; Vitti, G. C.; Pereira, H. S.; Menezes, G. M.; Tagliarini, C. H. Influência da compactação no desenvolvimento radicular de citrus: sugestão de método de avaliação e recomendação de manejo. Laranja, v.15, p.251-262, 1994.

Moraes, M. H.; Benez, S. H. Efeitos de diferentes sistemas de preparo do solo em algumas propriedades físicas de uma terra roxa estruturada e na produção de milho para um ano de cultivo. Engenharia Agrícola, v.16, p.31-41, 1996.

Pacheco, E. P.; Cantalice, J. R. B. Análise de trilha no estudo dos efeitos de atributos físicos e matéria orgânica sobre a compressibilidade e resistência à penetração de um argissolo cultivado com cana-de-açúcar. Revista Brasileira Ciência do Solo, v.35, p.417-428, 2011. 
Perusi, M. C.; Carvalho, W. A. Avaliação da estabilidade de agregados de Argissolos em diferentes sistemas de uso e manejo no município de Anhumas - SP. Energia na Agricultura, Botucatu, v.22, p.94-111, 2007.

Raij, B. van; Andrade, J. C.; Cantarella, H.; Quaggio, J.A. Análise química para avaliação da fertilidade de solos tropicais. Campinas: Instituto Agronômico, 2001. 285p.

Roque, A. A. O.; Souza, Z. M.; Barbosa, R. S.; Souza, G. S. Controle de tráfego agrícola e atributos físicos do solo em área cultivada com cana-de-açúcar. Pesquisa Agropecuária Brasileira, v.45, p.744-750, 2010.

Santos, G. G.; Silveira, P. M.; Marchão, R. L.; Becquer, T.; Balbino, L. C. Macrofauna edáfica associada a plantas de cobertura em plantio direto em um Latossolo Vermelho do cerrado. Pesquisa Agropecuária Brasileira, v.43, p.115-122, 2008.
Silva, F. de F. da; Freddi, O. da S.; Centurion, J. F.; Aratani, R. G.; Andrioli, F. F.; Andrioli, I. Propriedades físicas de um Latossolo Vermelho cultivado no sistema plantio direto. Irriga, v.13, p.191-204, 2008.

Soane, B. D. The role of organic matter in soil compactability: A review of some practical aspects. Soil Tillage Research, v.16, p.179-201, 1990

Veiga, M. da; Horn, R.; Reinert, D. J.; Reichert, J. M. Soil compressibility and penetrability of an Oxisol from southern Brazil, as affected by long-term tillage systems. Soil and Tillage Research, v.92, p.104-113, 2007.

Zalamena, J. Impacto do uso da terra nos atributos químicos e físicos de solos do rebordo do Planalto - RS. Santa Maria: UFSM, 79p. 2008. Dissertação Mestrado 